\title{
Are birth weight and maternal smoking during pregnancy associated with malnutrition and excess weight among school age children?
}

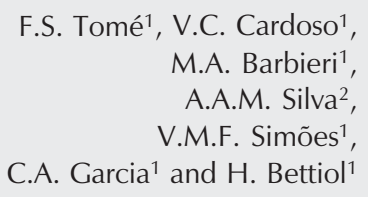

\author{
${ }^{1}$ Departamento de Puericultura e Pediatria, Faculdade de Medicina de Ribeirão Preto, \\ Universidade de São Paulo, Ribeirão Preto, SP, Brasil \\ ${ }^{2}$ Departamento de Saúde Pública, Universidade Federal do Maranhão, São Luís, \\ MA, Brasil
}

\author{
Correspondence \\ H. Bettiol \\ Departamento de Puericultura \\ e Pediatria, FMRP, USP \\ Avenida Bandeirantes, 3900 \\ 14049-900 Ribeirão Preto, SP \\ Brasil \\ Fax: +55-16-3602-2700 \\ E-mail: hbettiol@fmrp.usp.br \\ Research supported by CNPq, Nestlé \\ Comercial e Industrial Ltda., and \\ FAPESP (No. 05/54463-5).
}

$\ldots \ldots \ldots \ldots \ldots \ldots$

Received November 20, 2006 Accepted June 21, 2007

\begin{abstract}
In the late 1980's child malnutrition was still prevalent in Brazil, and child obesity was beginning to rise in the richest regions of the country. To assess the extent of the nutritional transition during the period and the influence of birth weight and maternal smoking on the nutritional condition of schoolchildren, we estimated the prevalence of excess weight and malnutrition in a cohort of Brazilian schoolchildren from 1987 to 1989 . We calculated the body mass index (BMI) of 8- to 10-year-old schoolchildren born in Ribeirão Preto in 1978/79. We considered children with a BMI $<5$ th percentile (P5) to be malnourished, children with $\mathrm{P} 5 \geq \mathrm{BMI}<\mathrm{P} 85$ to be thin and normal, and children with $\mathrm{BMI} \geq \mathrm{P} 85$ to be overweight. We evaluated the association of these nutritional disorders with birth factors (infant weight, sex, preterm delivery, number of pregnancies, maternal smoking during pregnancy, marital status, and schooling) and type of school using nominal logistic regression. A total of 2797 schoolchildren were evaluated. There was a significant prevalence of malnutrition $(9.5 \%)$ and excess weight already tended to increase $(15.7 \%)$, while $6.4 \%$ of the children were obese. Excess weight was more prevalent among children attending private schools (odds ratio, $\mathrm{OR}=2.27$ ) and firstborn children $(\mathrm{OR}=1.69)$. Maternal smoking during pregnancy protected against malnutrition $(\mathrm{OR}=0.56)$, while children with lower birth weight were at higher risk for malnutrition $(\mathrm{OR}=4.23)$. We conclude that a nutritional transition was under way while malnutrition was still present, but excess weight and related factors were already emerging.
\end{abstract}

Key words

- Child malnutrition

- Child obesity

- Body mass index

- Schoolchildren

- Socioeconomic level

.................... 


\section{Introduction}

Nutritional transition, representing a change from a high prevalence of malnutrition and infectious diseases to the predominance of obesity and non-communicable chronic diseases (1), accompanies the processes of rapid urbanization and of economic and technological growth that modify dietary, physical activity and life style patterns (2).

Nutritional transition has been observed in Brazil for more than 30 years. Two nationally representative cross-sectional studies conducted in 1974 and 1989 have shown that malnutrition, although still relevant among children of the poorest economic strata, has been declining among children and adults of all social strata (3). During this time, an increase in obesity has been observed among men and women. Income and body mass index (BMI) were inversely correlated among wealthier women, while the highest prevalence of obesity was observed in the middle income group. The poorest women, with a prevalence of obesity of $9.7 \%$, could no longer be considered to be protected against obesity. The 1989 study showed that malnutrition among children and obesity among women were the major nutritional problems in the country, with obesity being expressive among adults and children in the urban areas of the South and Southeast. Malnutrition was prevalent only among men, women and children living in rural areas of the Northeast, the poorest region of Brazil (4). In 1990, the Instituto Nacional de Alimentação e Nutrição (National Institute of Diet and Nutrition) pointed out that obesity was already present in $16 \%$ of children (5).

Child obesity, in addition to being related to genetic and life style factors, is related to factors present during intrauterine life or arising during the earliest ages (6-13). The relation between birth size and the risk to develop obesity is still controversial.
Barker (14) reported that children of low weight at birth or during childhood have a higher prevalence of risk factors for cardiovascular disease and type 2 diabetes during adulthood than children with a normal birth weight and adequate growth during childhood. This investigator detected a U-shaped association between birth measurements and risk factors for coronary disease and high mortality due to this disease among adults. Both the lowest and the highest measurement values at birth involved a greater proportion of people with risk factors for these diseases (15). However, this U-shaped association was not observed between groups of birth weight and length according to gestational age and excess weight in young men (16).

An association between maternal smoking during pregnancy and excess weight in other phases of life has been reported, with this effect being dose-dependent in childhood (9) and independent of intrauterine growth restriction, and being attributable to the specific effect of cigarettes (6). Apparently, only mothers who smoke early during pregnancy have children with excess weight (17). The association between obesity and maternal smoking is observed in early childhood $(7,18)$ and also during school age (19) and is stronger at later ages (18).

The objective of the present study was to estimate the prevalence of excess weight (overweight and obesity) and malnutrition in a cohort of Brazilian children of school age between 1987 and 1989 based on BMI in order to assess the extent of the nutritional transition during this period, and to determine the influence of birth weight and of maternal smoking on the nutritional condition of the schoolchildren.

\section{Material and Methods}

The present study was conducted in 1987/ 89 during the second evaluation of the cohort of liveborns delivered at hospitals in 
Ribeirão Preto, SP, Brazil, in 1978/79, when the participants were of school age.

The data of the 6827 newborn singleton infants were collected between June 1978 and May 1979 at the 8 hospitals in the city of Ribeirão Preto which provided maternity services at the time and which attended jointly all social classes. Questionnaires containing items about parents, income, pregnancy and delivery, the newborn infant and child death (when it occurred), ethnic group, and human reproduction were elaborated and answered by the mothers after delivery. The information was obtained by interviewing the mothers and by consulting the medical records of the maternity hospitals containing the anthropometric measurements of the newborn infants (weight, length, and head circumference at birth). The data were collected by trained personnel and the anthropometric measurements were made using standard methods (20). Details regarding the methodology of the initial study have been published $(21,22)$.

Taking into consideration the fact that Ribeirão Preto presented high rates of access to school (86\%) and literacy and low emigration rates (less than 1\%) (22) during the period of reevaluation of the children, the data for the schoolchildren were collected between the second semester of 1987 and the end of 1989 at state, municipal and private schools (76 schools). A total of 2898 children aged 8 to 11 years $(42.4 \%$ of the original cohort) for whom birth and school age information was available were evaluated. Data concerning age, sex, type of school, and anthropometric measurements of the children (weight, height and head circumference) were recorded on individual cards by standardized techniques (20) and were collected by personnel trained by the coordinators of the study.

The BMI values of the children were calculated and the children were classified as follows according to the percentiles defined by Must et al. (23): malnourished,
BMI below the 5th percentile $(<\mathrm{P} 5)$; thin, $\mathrm{P} 5$ to $<\mathrm{P} 50$; normal, P50 to $<\mathrm{P} 85$; overweight, $\mathrm{P} 85$ to $<\mathrm{P} 95$; obese, $\geq \mathrm{P} 95$. For this calculation the ages of the schoolchildren were defined as complete years at 12-month intervals (the 6 months preceding and the 6 months following each age in complete years): 8 years (101 to 102 months), 9 years (103 to 114 months), 10 years (115 to 126 months).

Birth weight, in grams, was defined as an independent variable and categorized as follows: <2500; 2500ト3000; 3000ト3500; $3500 \vdash 4000$ and $\geq 4000 \mathrm{~g}$. The control variables obtained at birth were: newborn's sex, number of pregnancies (1, 2 or 3, 4 or more), maternal smoking habit during pregnancy (yes; no), preterm birth (yes if the duration of gestation was $<37$ weeks; no, if $\geq 37$ complete weeks); mother's marital status (with or without a companion), and maternal schooling in complete years ( 0 to 4,5 to 8,9 to $11, \geq 12$ years). The control variable obtained at school age was type of school: public in a peripheral neighborhood, paid private, free private (philanthropic), and public in an intermediate neighborhood. Peripheral neighborhoods were those designed for popular housing projects consisting of small houses without any extras such as a surrounding wall or a patio, with no finishing and built on small lots. There were several slums. Basic sanitation was present in about $70 \%$ of the dwellings and public day-care centers were concentrated in these neighborhoods. Intermediate neighborhoods were of two types: those with a medium construction quality, with full basic sanitation and permitting the construction of residential buildings with up to 3 stories as well as the functioning of commercial enterprises usually consisting of private health clinics, small supermarkets, bars, bakeries, and unsophisticated diversified commerce. The other type consisted of medium quality neighborhoods but simpler than the previous group, comprising most of the traditional neighborhoods close to downtown, with quite simple old 
and new buildings, and also popular housing projects that had already been improved in terms of construction, with complete basic sanitation, health centers, assistance daycare centers, and commerce consisting of bars, bakeries, and simple supermarkets.

Gestational age was calculated according to date of last normal menstrual period reported by the mother during the postpartum interview. When the date was unknown,

Table 1. Comparison of the characteristics of the cohort at birth with those who participated in the second phase of the study. Ribeirão Preto, 1978/79 and 1987/89.

\begin{tabular}{|c|c|c|c|}
\hline Variables & $\begin{array}{l}\text { Initial population } \\
\text { in } 1978 / 79 \text { (excluding } \\
257 \text { deaths up to the } \\
\text { 1st year) }(\mathrm{N}=6570 \text { ) }\end{array}$ & $\begin{array}{c}\text { Individuals not } \\
\text { interviewed in } \\
1987 / 89 \\
(\mathrm{~N}=3773)\end{array}$ & $\begin{array}{l}\text { Individuals } \\
\text { interviewed } \\
\text { in 1987/89 } \\
(\mathrm{N}=2797)\end{array}$ \\
\hline \multicolumn{4}{|l|}{ Birth weight* } \\
\hline$<2500$ & $391(5.9 \%)$ & $255(6.9 \%)$ & $136(4.9 \%)$ \\
\hline 2500 to 2999 & $1368(20.8 \%)$ & $817(21.6 \%)$ & $551(19.7 \%)$ \\
\hline 3000 to 3499 & $2670(40.6 \%)$ & $1514(40.1 \%)$ & $1156(41.3 \%)$ \\
\hline 3500 to 3999 & $1695(25.8 \%)$ & $938(24.8 \%)$ & 757 (27.0\%) \\
\hline$\geq 4000$ & $445(6.8 \%)$ & $249(6.6 \%)$ & $196(7.0 \%)$ \\
\hline Missing & $1(0.1 \%)$ & $0(0.0 \%)$ & $1(0.1 \%)$ \\
\hline \multicolumn{4}{|l|}{ Sex } \\
\hline Male & $3375(51.4 \%)$ & 1960 (51.9\%) & 1415 (50.6\%) \\
\hline Female & 3195 (48.6\%) & $1813(48.1 \%)$ & 1382 (49.4\%) \\
\hline \multicolumn{4}{|l|}{ Preterm birth } \\
\hline Yes & $398(6.1 \%)$ & $239(6.3 \%)$ & $159(5.7 \%)$ \\
\hline No & $6172(93.9 \%)$ & $3534(93.7 \%)$ & $2638(94.3 \%)$ \\
\hline \multicolumn{4}{|c|}{ Maternal schooling (years) } \\
\hline 0 to 4 & $3245(49.4 \%)$ & $2020(53.5 \%)$ & $1225(43.8 \%)$ \\
\hline 5 to 8 & $1627(24.8 \%)$ & $856(22.7 \%)$ & $771(27.6 \%)$ \\
\hline 9 to 11 & $878(13.4 \%)$ & $441(11.7 \%)$ & $437(15.6 \%)$ \\
\hline$\geq 12$ & $659(10.0 \%)$ & $357(9.5 \%)$ & $302(10.8 \%)$ \\
\hline Missing & $161(2.4 \%)$ & $99(2.6 \%)$ & $62(2.2 \%)$ \\
\hline \multicolumn{4}{|l|}{ Mother's marital status* } \\
\hline With a companion & $6065(92.3 \%)$ & $3440(91.2 \%)$ & 2625 (93.9\%) \\
\hline Without a companion & $431(6.6 \%)$ & $287(7.6 \%)$ & $144(5.1 \%)$ \\
\hline Missing & $74(1.1 \%)$ & $46(1.2 \%)$ & $28(1.0 \%)$ \\
\hline \multicolumn{4}{|l|}{ No. of pregnancies* } \\
\hline 1 & 2117 (32.2\%) & $1150(30.5 \%)$ & $967(34.6 \%)$ \\
\hline 2 to 3 & $2788(42.4 \%)$ & $1579(41.9 \%)$ & 1209 (43.2\%) \\
\hline$\geq 4$ & $1489(22.7 \%)$ & $932(24.7 \%)$ & 557 (19.9\%) \\
\hline Missing & $176(2.7 \%)$ & $112(2.9 \%)$ & $64(2.3 \%)$ \\
\hline \multicolumn{4}{|l|}{ Maternal smoking* } \\
\hline Yes & $1836(27.9 \%)$ & 1127 (29.9\%) & 709 (25.4\%) \\
\hline No & $4553(69.3 \%)$ & 2529 (67.0\%) & 2024 (72.4\%) \\
\hline Missing & $181(2.8 \%)$ & 117 (3.1\%) & $64(2.2 \%)$ \\
\hline
\end{tabular}

Data are reported as number with percent in parentheses. The "missing" category was not included in the tests.

${ }^{*} P<0.05$ comparing those interviewed with those not interviewed in 1987/1989 (chisquare test). the duration of pregnancy was implausible (less than 20 or more than 50 weeks), or birth weight was incompatible with gestational age, the latter was imputed in a linear regression model. Birth weight, parity, newborn's sex, and family income were used to impute gestational age (24).

Thirty-seven twin births and 64 children ( 36 boys and 28 girls) who were 11 years old at the time of school evaluation were excluded from the study since these 64 children might have already started the pubertal growth spurt. Thus, a total of 2797 children (1415 boys and 1382 girls) were left in the study.

In the exploratory analysis of the data, frequency tables were constructed and the chi-square test was applied to evaluate the association between qualitative variables. A polytomic (nominal) logistic regression model was constructed since the response variable considered (BMI) was reclassified into three categories $\mathrm{BMI}<\mathrm{P}$ 5: malnourished; $\mathrm{BMI}$ from $\mathrm{P} 5$ to $<\mathrm{P} 85$ : normal; $\mathrm{BMI} \geq \mathrm{P} 85$ : excess weight, with birth weight being the independent variable. The control variables described previously (newborn sex, number of pregnancies, maternal smoking during pregnancy, preterm birth, mother's marital status, maternal schooling, type of school) were used for adjusted analysis. All analyses were performed using the Minitab 14 statistical package.

\section{Results}

In the present study, the most prevalent age group was 10 years $(68.6 \%)$, with $30.9 \%$ of the children being 9 years old and only $0.5 \%$ being 8 years old. A total of 266 children $(9.5 \%)$ were classified as malnourished, $2090(74.8 \%)$ as thin or normal and 438 $(15.7 \%)$ as having excess weight, with 261 (9.3\%) of them being overweight (BMI from P85 to P94.9) and 177 (6.4\%) being obese (BMI $\geq$ P95).

The children with lowest birth weight 
whose mothers had low schooling, had no companion, were multiparous, or smoked during pregnancy had lower follow-up rates (Table 1).

Table 2 presents the distribution of BMI according to the characteristics of the study population. There was association between birth weight and BMI at school age; newborn infants of low birth weight $(<2500 \mathrm{~g})$ presented a greater proportion of malnutrition $(14 \%)$ than of excess weight $(9.5 \%)$, whereas the percentage of newborn infants weighing more than $4000 \mathrm{~g}$ who were malnourished was small (3.1\%) and one quarter of them had excess weight (24.5\%). Children whose mothers had a high level of schooling ( $\geq 12$ years) and who were firstborn presented higher than expected proportions of excess weight (26.2 and 18.6\%, respectively). Children of mothers without a companion had a low proportion of excess weight $(9.1 \%)$ and a high proportion of malnutrition (14\%). Only $7.2 \%$ of children of mothers who smoked were malnourished at 8-10 years of age. Children attending private schools presented low malnutrition (3.9\%) and a high prevalence of excess weight (25.9\%).

Table 3 presents the crude odds ratio (OR) for the birth weight variable and for the control variables in relation to the BMI of malnourished children and of children with excess weight, with the category of normal children being considered as a reference. Low birth weight children had a higher risk to develop malnutrition during school age $(\mathrm{OR}=4.32)$ than children of normal birth weight, whereas an inverse relationship was observed for excess weight. Children of mothers who smoked presented a lower risk for malnutrition at 8-10 years of age $(\mathrm{OR}=$ 0.65 ), with no significant relationship being observed between maternal smoking and excess weight in this group of schoolchildren. There was an association of excess weight with firstborn children $(\mathrm{OR}=1.93)$, as well as with type of school attended by the child. Children attending private schools were at lower risk for malnutrition and at higher risk for excess weight compared to normal children, with the latter effect being also observed in public schools of intermediate neighborhoods. Mothers with low schooling (up to 4 years) were at higher risk to have malnourished children $(\mathrm{OR}=2.18)$ and at lower risk to have children with excess weight $(\mathrm{OR}=0.42)$, as also observed for mothers

Table 2. Frequency of early life and childhood variables according to body mass index percentile distribution of the schoolchildren.

\begin{tabular}{|c|c|c|c|}
\hline \multirow[t]{2}{*}{ Variables } & \multicolumn{3}{|c|}{ Body mass index } \\
\hline & $<\mathrm{P} 5$ & P5 to P84.9 & $\geq \mathrm{P} 85$ \\
\hline \multicolumn{4}{|l|}{ Birth weight* } \\
\hline$<2500$ & $19(14.0 \%)$ & $104(76.5 \%)$ & $13(9.5 \%)$ \\
\hline 2500 to 2999 & $73(13.3 \%)$ & $417(75.8 \%)$ & $60(10.9 \%)$ \\
\hline 3000 to 3499 & $134(11.6 \%)$ & $856(74.0 \%)$ & $166(14.4 \%)$ \\
\hline 3500 to 3999 & $34(4.5 \%)$ & $570(75.5 \%)$ & $151(20.0 \%)$ \\
\hline$\geq 4000$ & $6(3.1 \%)$ & $142(72.4 \%)$ & $48(24.5 \%)$ \\
\hline \multicolumn{4}{|l|}{ Sex } \\
\hline Male & $125(8.9 \%)$ & $1063(75.2 \%)$ & 225 (15.9\%) \\
\hline Female & $141(10.2 \%)$ & $1027(74.4 \%)$ & $213(15.4 \%)$ \\
\hline \multicolumn{4}{|l|}{ Preterm birth } \\
\hline Yes & $20(12.6 \%)$ & $120(75.5 \%)$ & $19(11.9 \%)$ \\
\hline No & $246(9.3 \%)$ & $1970(74.8 \%)$ & 419 (15.9\%) \\
\hline \multicolumn{4}{|c|}{ Maternal schooling (years) ${ }^{*}$} \\
\hline 0 to 4 & $137(11.2 \%)$ & $939(76.7 \%)$ & $148(12.1 \%)$ \\
\hline 5 to 8 & $80(10.4 \%)$ & $575(74.6 \%)$ & $116(15.0 \%)$ \\
\hline 9 to 11 & $33(7.6 \%)$ & $319(73.3 \%)$ & $83(19.1 \%)$ \\
\hline$\geq 12$ & $14(4.6 \%)$ & $209(69.2 \%)$ & $79(26.2 \%)$ \\
\hline \multicolumn{4}{|l|}{ Mother's marital status* } \\
\hline With a companion & $245(9.3 \%)$ & $1959(74.7 \%)$ & $419(16.0 \%)$ \\
\hline Without a companion & $20(14.0 \%)$ & $110(76.9 \%)$ & $13(9.1 \%)$ \\
\hline \multicolumn{4}{|l|}{ No. of pregnancies* } \\
\hline 1 & $97(10.1 \%)$ & 689 (71.3\%) & $180(18.6 \%)$ \\
\hline 2 to 3 & $113(9.4 \%)$ & 907 (75.1\%) & 187 (15.5\%) \\
\hline$\geq 4$ & $54(9.7 \%)$ & $443(79.5 \%)$ & $60(10.8 \%)$ \\
\hline \multicolumn{4}{|l|}{ Maternal smoking* } \\
\hline Yes & $51(7.2 \%)$ & 547 (77.4\%) & $109(15.4 \%)$ \\
\hline No & $213(10.5 \%)$ & $1492(73.8 \%)$ & $318(15.7 \%)$ \\
\hline \multicolumn{4}{|l|}{ Type of school* } \\
\hline Philanthropic & $51(14.2 \%)$ & 269 (74.9\%) & $39(10.9 \%)$ \\
\hline Public IN & $134(9.1 \%)$ & $1096(74.4 \%)$ & $244(16.5 \%)$ \\
\hline Private & $16(3.9 \%)$ & $287(70.2 \%)$ & $106(25.9 \%)$ \\
\hline Public PN & $65(11.8 \%)$ & $438(79.3 \%)$ & 49 (8.9\%) \\
\hline Total & 266 (9.5\%) & 2090 (74.8\%) & $438(15.7 \%)$ \\
\hline
\end{tabular}

Data are reported as number with percent in parentheses. Public IN = public school in an intermediate neighborhood; Public $\mathrm{PN}=$ public school in a peripheral neighborhood. Totals may differ for some variables because of missing values.

${ }^{*} \mathrm{P}<0.05$ for comparison of body mass index with each variable (chi-square test). 
with 5 to 8 years of schooling $(\mathrm{OR}=2.08$ and 0.53 for malnutrition and excess weight, respectively). Children of mothers with 9 to 11 years of schooling were at lower risk for excess weight $(\mathrm{OR}=0.69)$. Newborn sex, mother's marital status and preterm birth were not associated with the nutritional status of schoolchildren.

Table 4 presents OR values adjusted with the nominal logistic regression model. There

Table 3. Crude odds ratio for the comparison between the malnourished $(<\mathrm{P} 5)$ and thin and normal (P5 to P84.9) classifications and between the excess weight ( $\geq P 85)$ and thin and normal (P5 to P84.9) classifications.

\begin{tabular}{|c|c|c|}
\hline \multirow[t]{2}{*}{ Variables } & \multicolumn{2}{|c|}{ Nutritional status } \\
\hline & $\begin{array}{c}<\text { P5 with P5 to P84.9 } \\
\text { OR }(95 \% \mathrm{Cl})\end{array}$ & $\begin{array}{c}\geq P 85 \text { with P5 to P84.9 } \\
\text { OR }(95 \% \mathrm{Cl})\end{array}$ \\
\hline \multicolumn{3}{|l|}{ Birth weight } \\
\hline$<2500$ & $4.32(1.67 ; 11.20)$ & $0.37(0.19 ; 0.72)$ \\
\hline 2500 to 2999 & $4.14(1.76 ; 9.73)$ & $0.43(0.28 ; 0.65)$ \\
\hline 3000 to 3499 & $3.70(1.60 ; 8.56)$ & $0.57(0.40 ; 0.83)$ \\
\hline 3500 to 3999 & $1.41(0.58 ; 3.43)$ & $0.78(0.54 ; 1.14)$ \\
\hline$\geq 4000$ & 1 & 1 \\
\hline \multicolumn{3}{|l|}{ Sex } \\
\hline Male & $0.86(0.66 ; 1.11)$ & $1.02(0.83 ; 1.25)$ \\
\hline Female & 1 & 1 \\
\hline \multicolumn{3}{|l|}{ Preterm birth } \\
\hline Yes & $1.33(0.82 ; 2.18)$ & $0.74(0.45 ; 1.22)$ \\
\hline No & 1 & 1 \\
\hline \multicolumn{3}{|l|}{ Maternal schooling (years) } \\
\hline 0 to 4 & $2.18(1.23 ; 3.85)$ & $0.42(0.31 ; 0.57)$ \\
\hline 5 to 8 & $2.08(1.15 ; 3.74)$ & $0.53(0.38 ; 0.74)$ \\
\hline 9 to 11 & $1.54(0.81 ; 2.96)$ & $0.69(0.48 ; 0.98)$ \\
\hline$\geq 12$ & 1 & 1 \\
\hline \multicolumn{3}{|l|}{ Mother's marital status } \\
\hline With a companion & $0.69(0.42 ; 1.13)$ & $1.81(1.01 ; 3.25)$ \\
\hline Without a companion & 1 & 1 \\
\hline \multicolumn{3}{|l|}{ No. of pregnancies } \\
\hline 1 & $1.15(0.81 ; 1.64)$ & $1.93(1.41 ; 2.64)$ \\
\hline 2 to 3 & $1.02(0.72 ; 1.44)$ & $1.52(1.11 ; 2.08)$ \\
\hline$\geq 4$ & 1 & 1 \\
\hline \multicolumn{3}{|l|}{ Maternal smoking } \\
\hline Yes & $0.65(0.47 ; 0.90)$ & $0.93(0.74 ; 1.19)$ \\
\hline No & 1 & 1 \\
\hline \multicolumn{3}{|l|}{ Type of school } \\
\hline Public PN & 1 & 1 \\
\hline Philanthropic & $1.28(0.86 ; 1.90)$ & $1.30(0.83 ; 2.03)$ \\
\hline Public IN & $0.82(0.60 ; 1.13)$ & $1.99(1.44 ; 2.76)$ \\
\hline Private & $0.38(0.21 ; 0.66)$ & $3.30(2.28 ; 4.78)$ \\
\hline
\end{tabular}

Data are reported as odds ratio (OR) with $95 \%$ confidence intervals $(\mathrm{Cl})$ in parentheses. Public PN = public school in a peripheral neighborhood. Public IN = public school in an intermediate neighborhood. were practically no changes compared to non-adjusted analysis, except for maternal schooling, which was no longer associated with the nutritional status of the schoolchildren.

\section{Discussion}

Almost double the expected percentage of malnourished children $(9.5 \%)$ and a percentage slightly above the expected value $(15.7 \%)$ of schoolchildren with excess weight were detected in the present study, denoting a still high prevalence of malnourished children in the years from 1987 to 1989, although the prevalence of obesity already tended to increase in population studies conducted during the same period $(4,5)$.

The present findings indicate that there was a selective loss of follow-up of the initial cohort since socially disadvantaged individuals, i.e., children of mothers with lower schooling, without a companion, with many children and who smoked during pregnancy, in addition to low birth weight (LBW) children had lower participation rates in the study. However, even though the differences were significant due to the large sample size, percent differences were small. Since the Ribeirão Preto region is developed and the rate of access to school is high, possibly disadvantaged children had a lower access to school or had higher drop-out rates starting from second grade of elementary school when they reached the lowest age covered by the study ( 8 years). Thus, the prevalence of malnutrition may have been slightly underestimated in the present study.

In the years from 1987 to 1989 , Brazil was going through a process of political and social reorganization, with a progressive improvement of the economy and of the resources for health promotion and disease prevention and a greater access to industrialized goods (25). However, the reduction of birth rates, the improvement of basic sanitation, the protection against infectious dis- 
eases mainly due to immunization, the increased schooling of the mothers, the changes in the profile of dietary consumption, and the access to basic health actions have led to a change in the epidemiological profile of the Brazilian population, especially regarding the nutritional problems $(26,27)$. A change in the prevalence of obesity was clearly occurring (28). The prevalence of child obesity was already increasing in the country, especially among the upper social classes $(3,5)$. However, significant rates of malnutrition were still observed, showing that the environmental factors determining this disease were still highly prevalent during childhood.

The present data reflect this period of change since a higher than expected percentage of malnourished children was observed, although an increase in the prevalence of excess weight slightly above the expected upper limit was already emerging and was associated with a higher socioeconomic level. The relationship observed in this respect was that richer children (those studying in private schools and in public schools in intermediate neighborhoods) were at lower risk for malnutrition and at higher risk for obesity, as is still the case in emerging countries such as Indonesia, where malnutrition is related to poverty, whereas obesity is more related to prosperity (29). Recent studies conducted in Brazil have demonstrated that the prevalence of excess weight in children is still higher in the more privileged socioeconomic strata (30-32), whereas in developed countries this prevalence is higher among children of low socioeconomic level (33).

LBW was associated with a higher risk to develop malnutrition, with a progressive reduction of the risk for greater birth weight. This association was detected in previous studies (34), although recent investigations have shown an inverse relationship, i.e., LBW predisposes to the development of obesity in childhood and is also associated with a higher risk for cardiovascular diseases during adult age $(14,35)$. These findings are explained by the existence of a period of development when the organic systems are plastic and sensitive to the action of environmental agents, followed by loss of plasticity and by the establishment of fixed functional capacity. In this respect, the intrauterine period is highly significant since it is the time of development of different organic systems

Table 4. Adjusted odds ratio for the comparison between the malnourished $(<\mathrm{P} 5)$ and thin and normal (P5 to P84.9) classifications and between the excess weight ( $\geq P 85)$ and thin and normal (P5 to P84.9) classifications.

\begin{tabular}{|c|c|c|}
\hline \multirow[t]{2}{*}{ Variables } & \multicolumn{2}{|c|}{ Nutritional status } \\
\hline & $\begin{array}{c}<\text { P5 with P5 to P84.9 } \\
\text { OR }(95 \% \mathrm{Cl})\end{array}$ & $\begin{array}{c}\geq P 85 \text { with } \mathrm{P} 5 \text { to } \mathrm{P} 84.9 \\
\text { OR }(95 \% \mathrm{Cl})\end{array}$ \\
\hline \multicolumn{3}{|l|}{ Birth weight } \\
\hline$<2500$ & $4.23(1.54 ; 11.62)$ & $0.41(0.19 ; 0.86)$ \\
\hline 2500 to 2999 & $4.22(1.78 ; 9.98)$ & $0.44(0.28 ; 0.69)$ \\
\hline 3000 to 3499 & $3.73(1.61 ; 8.66)$ & $0.62(0.42 ; 0.91)$ \\
\hline 3500 to 3999 & $1.40(0.57 ; 3.41)$ & $0.78(0.53 ; 1.15)$ \\
\hline$\geq 4000$ & 1 & 1 \\
\hline \multicolumn{3}{|l|}{ Sex } \\
\hline Male & $0.91(0.70 ; 1.18)$ & $0.96(0.77 ; 1.19)$ \\
\hline Female & 1 & 1 \\
\hline \multicolumn{3}{|l|}{ Preterm birth } \\
\hline Yes & $1.02(0.57 ; 1.81)$ & $1.12(0.64 ; 1.97)$ \\
\hline No & 1 & 1 \\
\hline \multicolumn{3}{|c|}{ Maternal schooling (years) } \\
\hline 0 to 4 & $1.49(0.78 ; 2.84)$ & $0.70(0.48 ; 1.04)$ \\
\hline 5 to 8 & $1.45(0.76 ; 2.78)$ & $0.74(0.50 ; 1.08)$ \\
\hline 9 to 11 & $1.26(0.64 ; 2.49)$ & $0.81(0.55 ; 1.17)$ \\
\hline$\geq 12$ & 1 & 1 \\
\hline \multicolumn{3}{|l|}{ Mother's marital status } \\
\hline With a companion & $0.73(0.43 ; 1.22)$ & $1.71(0.94 ; 3.12)$ \\
\hline Without a companion & 1 & 1 \\
\hline \multicolumn{3}{|l|}{ No. of pregnancies } \\
\hline 1 & $1.26(0.86 ; 1.84)$ & $1.69(1.21 ; 2.36)$ \\
\hline 2 to 3 & $1.12(0.78 ; 1.60)$ & $1.35(0.98 ; 1.87)$ \\
\hline$\geq 4$ & 1 & 1 \\
\hline \multicolumn{3}{|l|}{ Maternal smoking } \\
\hline Yes & $0.56(0.40 ; 0.78)$ & $1.07(0.84 ; 1.37)$ \\
\hline No & 1 & 1 \\
\hline \multicolumn{3}{|l|}{ Type of school } \\
\hline Public PN & 1 & 1 \\
\hline Philanthropic & $1.24(0.82 ; 1.87)$ & $1.17(0.74 ; 1.84)$ \\
\hline Public IN & $0.86(0.62 ; 1.20)$ & $1.75(1.25 ; 2.46)$ \\
\hline Private & $0.48(0.25 ; 0.91)$ & $2.27(1.47 ; 3.53)$ \\
\hline
\end{tabular}

Data are reported as odds ratio (OR) with $95 \%$ confidence intervals $(\mathrm{Cl})$ in parentheses. Public PN = public school in a peripheral neighborhood. Public IN = public school in an intermediate neighborhood. 
when metabolic, physiological and structural changes may become permanent (the "programming" theory) (14).

The influences that restrict fetal growth during intrauterine life promote adaptive changes in the fetus regarding its energy reserves, which are essential for its survival in this environment. However, when nutrients are offered in abundance after birth this is interpreted as a lack of adaptation, leading to obesity. In several studies, children with LBW presented a postnatal catch-up that predisposed them to an increased risk to develop childhood obesity and cardiovascular diseases during adult life $(10,14,35)$. A possible explanation for the discordant findings of the present study in this respect is that this relation applies to modern societies characterized by a more sedentary life style and by eating habits involving more caloric foods (5). The significant rates of malnutrition observed during the period of the present study suggest that the environmental factors causing malnutrition were still present and the life and dietary styles that might lead children of LBW to present a catch-up that would favor the development of excess weight had not been well established. This hypothesis is corroborated by the observation that the boys of this cohort with a smaller birth weight had a lower BMI at 18 years of age (36), with the U-shaped association reported by others (15) being absent. The predominance of malnutrition during earlier phases of life in most of these children probably contributed to their lower BMI at the end of adolescence. However, among the boys who had intrauterine growth restriction and had excess weight at school age, the BMI at 18 years was higher than that of boys who had normal intrauterine growth and normal BMI at school age (37). This finding suggests that for these children with intrauterine growth restriction excess weight at school age caused disequilibrium in the adaptive processes developed for intrauterine survival and was deleterious for health in later life (38).

Children born to mothers who smoked during pregnancy had a lower risk to develop childhood malnutrition. A recent review on prenatal programming of childhood overweight and obesity pointed out that the eight selected studies which examined the relationship between prenatal exposure to maternal smoking and childhood overweight and obesity found fair to good evidence in support of a causal relationship between prenatal tobacco exposure and fatness in childhood (39). The association of prenatal exposure to tobacco with offspring obesity has been observed in studies both at early ages such as 3 years $(7,17)$ and at the age when the child starts school (5 and 6 years) $(9,19)$ or at 8 years of age, even though in the last study (18) the effect was more modest. Children of smoking mothers, although smaller at birth than children born to non-smoking mothers, present an accelerated growth during the first 12 years of life $(10,40)$. The relationship between maternal smoking and accelerate growth is not influenced by other factors such as breast-feeding, birth weight or postnatal smoking habit since the association persisted even after adjustment for these factors, being explained by physiological or structural changes provoked by the substances present in cigarettes that occur during the period of greatest plasticity of an individual. The relationship between smoking and the adaptive changes it produces is demonstrated by the existence of a causal relation between the number of cigarettes smoked by the mother and an increased risk of higher BMI values of the schoolchildren, as reported elsewhere (6). We may speculate that in this population studied at school age and still presenting significant rates of malnutrition it was not possible to observe the effect of the metabolic changes provoked by smoking that lead to excess weight at later ages, but that signs of this possibility in the future were already present since these children were protected from malnutrition. This 
hypothesis is strengthened by the observation that conscripts of this same cohort whose mothers had smoked during pregnancy had a higher BMI at 18 years of age (36).

We observed that firstborn children were at a higher risk of excess weight. In a Swedish study (16) the risk for excess weight and obesity was slightly higher at 18 years of age among men from families with an only child than among men from families with two children, and increased again among children of families with three or more children. Another study has shown that these children are thinner at birth but catch up in growth during the first year of life, becoming heavier and taller than children that are not firstborns (10). The explanations for these findings are closely similar to those found for LBW and maternal smoking habit. The fact that these children had a lower birth weight compared to controls may reflect the occurrence of adaptive changes during the intra- uterine period that increase the risk for obesity when there is abundance of food after birth (10). However, firstborn children live as only children for a period of time, a fact that may reflect a greater offer of food, greater attention and lack of experience with child care on the part of the mother compared to children born after subsequent pregnancies.

We conclude that changes in the nutritional patterns of the population were already evident in 1987 and 1989 . Child malnutrition was still present but excess weight and related factors were emerging. LBW favored a greater risk of malnutrition during school age and was not related to a greater risk of excess weight, whereas maternal smoking during pregnancy protected from malnutrition but was not associated with excess weight. Excess weight became an emergent problem in the more privileged social classes and among firstborn children.

\section{References}

1. Rivera JA, Barquera S, Gonzalez-Cossio T, Olaiz G, Sepulveda J. Nutrition transition in Mexico and in other Latin American countries. Nutr Rev 2004; 62: S149-S157.

2. Popkin BM. The nutrition transition in low-income countries: an emerging crisis. Nutr Rev 1994; 52: 285-298.

3. Monteiro CA, Mondini L, de Souza AL, Popkin BM. The nutrition transition in Brazil. Eur J Clin Nutr 1995; 49: 105-113.

4. Mondini L, Monteiro CA. The stage of nutrition transition in different Brazilian regions. Arch Latinoam Nutr 1997; 47: 17-21.

5. Brasil, Ministério da Saúde, Instituto Nacional de Alimentação e Nutriçao. Pesquisa Nacional sobre Saúde e Nutrição. Perfil de crescimento da População Brasileira de 0 a 25 anos. Brasília: INAM; 1990.

6. Wideroe M, Vik T, Jacobsen G, Bakketeig LS. Does maternal smoking during pregnancy cause childhood overweight? Paediatr Perinat Epidemiol 2003; 17: 171-179.

7. Adams AK, Harvey HE, Prince RJ. Association of maternal smoking with overweight at age $3 \mathrm{y}$ in American Indian children. Am J Clin Nutr 2005; 82: 393-398.

8. Reilly JJ, Armstrong J, Dorosty AR, Emmett PM, Ness A, Rogers I, et al. Early life risk factors for obesity in childhood: cohort study. BMJ 2005; 330: 1357-1364.

9. von Kries R, Toschke AM, Koletzko B, Slikker W Jr. Maternal smoking during pregnancy and childhood obesity. Am J Epidemiol 2002; 156: 954-961.

10. Ong KK, Preece MA, Emmett PM, Ahmed ML, Dunger DB. Size at birth and early childhood growth in relation to maternal smoking parity and infant breast-feeding: longitudinal birth cohort study and analysis. Pediatr Res 2002; 52: 863-867.

11. Power C, Jefferis BJ. Fetal environment and subsequent obesity: a study of maternal smoking. Int J Epidemiol 2002; 31: 413-419.

12. Stettler N, Zemel BS, Kumanyika S, Stallings VA. Infant weight gain and childhood overweight status in a multicenter, cohort study. Pediatrics 2002; 109: 194-199.

13. O'Callaghan MJ, Williams GM, Andersen MJ, Bor W, Najman JM. Prediction of obesity in children at 5 years: a cohort study. $J$ Paediatr Child Health 1997; 33: 311-316.

14. Barker DJP. Programming the baby. In: Barker DJP (Editor), Mothers, babies and health in later life. Edinburgh: Elsevier Health Sciences; 1998. p 13-41.

15. Barker DPJ. The fetal origins of coronary heart disease. Acta Paediatr 1997; Suppl 422: 78-82.

16. Rasmussen $F$, Johansson M. The relation of weight, length and ponderal index at birth to body mass index and overweight among 18-year-old males in Sweden. Eur J Epidemiol 1998; 14: 373-380.

17. Oken E, Huh SY, Taveras EM, Rich-Edwards JW, Gillman MW. Associations of maternal prenatal smoking with child adiposity and blood pressure. Obes Res 2005; 13: 2021-2028.

18. Chen A, Pennell ML, Klebanoff MA, Rogan WJ, Longnecker MP. Maternal smoking during pregnancy in relation to child overweight: follow-up to age 8 years. Int J Epidemiol 2006; 35: 121-130.

19. Toschke AM, Koletzko B, Slikker W Jr, Hermann M, von Kries R. 
Childhood obesity is associated with maternal smoking in pregnancy. Eur J Pediatr 2002; 161: 445-448.

20. Falkner F. Office measurement of physical growth. Pediatr Clin North Am 1961; 8: 13-18.

21. Barbieri MA, Gomes UA, Barros-Filho AA, Bettiol H, Almeida LEA, Silva AAM. Saúde perinatal em Ribeirão Preto, SP, Brasil: a questão do método. Cad Saúde Pública 1989; 5: 376-387.

22. Cardoso VC, Simões VMF, Barbieri MA, Silva AAM, Bettiol H, Alves MTSSB, et al. Profile of three Brazilian birth cohort studies in Ribeirão Preto, SP and São Luís, MA. Braz J Med Biol Res 2007; 40: 1165-1176.

23. Must A, Dallal GE, Dietz WH. Reference data for obesity: 85th and 95th percentiles of body mass index (wt/ht2) and triceps skinfold thickness. Am J Clin Nutr 1991; 53: 839-846.

24. Silva AA, Lamy-Filho F, Alves MT, Coimbra LC, Bettiol H, Barbieri MA. Risk factors for low birthweight in north-east Brazil: the role of caesarean section. Paediatr Perinat Epidemiol 2001; 15: 257-264.

25. Batista FM, Rissin A. Nutritional transition in Brazil: geographic and temporal trends. Cad Saúde Pública 2003; 19 (Suppl 1): S181S191.

26. Monteiro CA, Mondini L, Souza ALH, Popkin BM. Da desnutrição para a obesidade: a transição nutricional no Brasil. In: Monteiro CA (Editor), Velhos e novos males da saúde no Brasil. 2nd edn. São Paulo: Editora Hucitec; 2000. p 247-255.

27. Benício MHD, Monteiro CA, Rosa TEC. Evolução da desnutrição, da pobreza e do acesso a serviços públicos. In: Monteiro CA (Editor), Velhos e novos problemas de saúde no Brasil. São Paulo: Editora Hucitec; 2000. p 141-152.

28. Sichieri R, Coitinho DC, Leao MM, Recine E, Everhart JE. High temporal, geographic, and income variation in body mass index among adults in Brazil. Am J Public Health 1994; 84: 793-798.

29. Julia M, van Weissenbruch MM, de Waal HA, Surjono A. Influence of socioeconomic status on the prevalence of stunted growth and obesity in prepubertal Indonesian children. Food Nutr Bull 2004; 25:
354-360.

30. Balaban G, Silva GA. Overweight and obesity prevalence in children and adolescents from a private school in Recife. J Pediatr 2001; 77 : 96-100.

31. Ribeiro IC, Taddei JA, Colugnatti F. Obesity among children attending elementary public schools in São Paulo, Brazil: a case-control study. Public Health Nutr 2003; 6: 659-663.

32. Guimarães LV, Barros MBA, Martins MSAS, Duarte EC. Fatores associados ao sobrepeso em escolares. Rev Nutr 2006; 19: 5-17.

33. Baughcum AE, Chamberlin LA, Deeks CM, Powers SW, Whitaker RC. Maternal perceptions of overweight preschool children. Pediatrics 2000; 106: 1380-1386.

34. Saigal S, Stoskopf BL, Streiner DL, Burrows E. Physical growth and current health status of infants who were of extremely low birth weight and controls at adolescence. Pediatrics 2001; 108: 407-415.

35. Ong KK, Ahmed ML, Emmett PM, Preece MA, Dunger DB. Association between postnatal catch-up growth and obesity in childhood: prospective cohort study. BMJ 2000; 320: 967-971.

36. Goldani MZ, Haeffner LSB, Agranonik M, Barbieri MA, Bettiol H, Silva AAM. Do early life factors influence body mass index in adolescents? Braz J Med Biol Res 2007; 40: 1231-1236.

37. Bettiol H, Sabbag Filho D, Haeffner LSB, Barbieri MA, Silva AAM, Portela $A$, et al. Do intrauterine growth restriction and overweight at primary school age increase the risk of elevated body mass index in young adults? Braz J Med Biol Res 2007; 40: 1237-1243.

38. Painter RC, Roseboom TJ, Bleker OP. Prenatal exposure to the Dutch famine and disease in later life: an overview. Reprod Toxicol 2005; 20: 345-352

39. Huang JS, Lee TA, Lu MC. Prenatal programming of childhood overweight and obesity. Matern Child Health J 2007; 11: 461-473.

40. Jones G, Riley M, Dwyer T. Maternal smoking during pregnancy, growth, and bone mass in prepubertal children. $J$ Bone Miner Res 1999; 14: 146-151. 